\title{
К вопросу о классификации экологических прав человека
}

\author{
Сучкова B.A.*
}

Экологические права составляют центральное звено международного эколого-правового статуса человека ${ }^{1}$. От их четкого определения, содержания, степени кодифицированности в международно-правовых актах во многом зависит решение задач обеспечения экологической безопасности, сохранения окружающей среды, рационального природопользования и перехода к эколого-бескризисной модели устойчивого социально-экономического развития. И хотя в юридической литературе можно встретить утверждение, что «...в целом вопрос о критериях отнесения прав к экологическим теоретически не так уж сложен» ${ }^{2}$, среди юристов-экологов и юристов-международников нет согласия относительно их правовой природы, происхождения, перечня и, что, на наш взгляд, наиболее важно, места в системе международно-признанных прав человека.

Экологическим правам посвящено уже немало работ отечественных правоведов. Однако всем им присущ один общий и, как нам представляется, существенный недостаток. В них экологические права анализируются с узко отраслевых позиций: конституционного права (С.А. Боголюбов, М.М. Бринчук, Л.Г. Клюканова, А.Б. Искоян, А.Г. Тарнавский, Г.В. Чубуков), экологического права (С.А. Боголюбов, М.М. Бринчук, М.И. Васильева, О.Л. Дубовик, А.А. Третьякова), международного экологического права (Е.А. Высторобец, М.Н. Копылов, Э.Ф. Нурмухаметова, Ю.С. Шемшученко), международной зациты прав человека (С.Н. Горбунов, В.О. Миронов, Б.А. Молчанов). Такое замыкание в рамках отдельной, пусть даже весьма значимой, отрасли права не позволяет взглянуть на проблему комплексно, раскрыв все ее аспекты.

\footnotetext{
* Сучкова Варвара Александровна - аспирантка кафедры международного права Российского университета дружбы народов.

${ }^{1}$ Тремя другими элементами эколого-правового статуса человека являгося: экологические обязанности, гарантии обеспечения соблюдения экологических прав и экологическая ответственность.

${ }^{2}$ Бринчук М.M. Теоретические основы экологических прав человека // Государство и право, 2004. № 5. С. 8.
} 
Поэтому в данной статье предпринята попытка раскрыть юридическое содержание экологических прав с точки зрения международного права в целом, чему в немалой степени призвана способствовать их правильная, научно обоснованная классификация.

В доктрине международного права вплоть до последнего времени господствовало деление прав человека на гражданские, политические (первое поколение прав), социальные, экономические и культурные (второе поколение прав). И только в середине 80-х гг. ХХ в. на волне «экологизации» международных отношений и под впечатлением положений Африканской Хартии прав человека и народов 1981 г. учеными-юористами впервые предпринимается попьтка обосновать существование третьего поколения прав человека - коллективньх прав, или прав солидарности, среди которых называстся, в частности, право на благоприятную окружающую среду ${ }^{3}$.

На фоне появляющихся в последние годы с завидной регулярностью публикаций об экологических правах граждан по национальному законодательству отдельных государств или их групп, несколько «бледными» выглядят попытки исследовать экологические права человека с точки зрения международного права. Не решают проблемы и многочисленные научные труды в области международной защиты прав человека, в которьх «экологическая составлягщая» таких прав растворяется и становится практически невидимой и в которых дело ограничивается, как правило, выведением «экологического подтекста» из ст. 3 и ст. 25 Всеобщей декларации прав человека 1948 г., в соответствии с которой «каждый человек имеет право на такой жизненный уровень, включая пищу, одежду, жилище, медицинский уход и необходимое социальное обслуживание, который необходим для поддержания здоровья и благосостояния его самого и его семьи ...». При этом исследователи упускают из вида, что «экологическое благополучие» может быть и неудовлетворительным, и низким, и попросту угрожающим, при том что сам указанный «жизненный уровень» одновременно может быть и удовлетворительным, и высоким, и попросту превосходным по всем остальным закрепленным в Декларации аспектам.

В этом случае их связь можно рассматривать как минимум в двух аспектах: во-первых, защита окружающей среды может являться сред-

\footnotetext{
${ }^{3}$ См.: Тузмухамедов Р.А. Третьепоколение прав человека» и права народов // Советское государство и право. 1986. № 5. С. 106-113; Vasak K. Le Droit international des droits del'homme // Revue des droits del'homme, 1972. № 5. P. 43-51.
} 
ством достижения цели выполнения стандартов в области прав человека. Поскольку деградация окружающей среды способствует нарушению прав человека на жизнь, здоровье и пропитание, действия, ведущие к деградации окружающей среды, являются нарушением международно-признанных прав человека. Во-вторьх, юридическая защита прав человека может стать средством достижения целей защиты и сохранения окружающей среды.

Если попытаться применить стандарты в области прав человека к существующим природозащитным механизмам, можно выделить 3 основных подхода: прежде всего это использование существующих прав для достижения экологических целей, далее это может быть пересмотр существующих прав с точки зрения защиты окружающей среды и затем - создание новьх прав именно экологического характера.

Использование существуюиих прав. Многие авторы (Д. Меррилс, Р. Черчилль, Т. Хардинг) отмечают, что права человека, которые уже защищены международными механизмами и националыными конституциями, играют большую роль в защите окружающей среды. Как пишет А. Бойл, существующие права, если они соблюдаются полностью, настолько эффективны, что создание новых норм будет в лучшем случае излишним, а в худшем - контрпродуктивным. Состав существующих прав на международном уровне достаточно полон и точен. Можно было бы сказать, продолжает он, что если бы правозашитники больше внимания уделяли ратификации существующих документов и выступали за их эффективную имплементацию в национальные законодательства, вместо рассуждений о создании новых норм, защита окружающей среды осуществлялась бы сама собой ${ }^{4}$.

Что касается гражданских и политических прав, то, по мнению А. Бойла, их важность заключается в том, что они укрепляют политический порядок, учитывающий интересы окружающей среды. Осуществление этих прав - включая право на жизнь, на объединение, на выражение мнений, на политическое участие, личную свободу, равенство и на обращение к правовым средствам защиты - означает не только право отдельных групп выступать против нанесения ущерба окружающей среде. Такие гарантии являются необходимой предпосылкой для привлечения внимания к проблемам окружающей среды и предложений по ее защите.

${ }^{4}$ CM.: Boyle A. The Role of International Human Rights Law in the Protection of the Environment. - In: Human Rights Approaches to Environmental Protection (eds. A. Boyle, M. Anderson). Oxford: Clarendon Press, 1998. P. 61. 
На этом основании Т. Хардинг делаег вывод о том, что права на окружающую среду могут «молча и без усилий» быть включены в правовую систему через существующие механизмы реализации политических прав. В то же время попытки прямого применения таких прав для достижения природозащитных целей часто не приводят к желаемому результату.

Экономические, социальные и культурные права, являясь правами «второго поколения», могут применяться главным образом через устанавливаемые ими материалыные стандарты благосостояния человека. Исследуя международные договоры в области прав человека, Р. Черчилль отмечает, что уже существующие положения о праве на здоровье, праве на адекватные условия жизни и праве на благоприятные условия труда прямо относятся к условиям окружающей среды. Право на здоровье, например, требует от государства принятия мер для защиты граждан от нездоровой окружающей среды и обеспечения качества окружающей среды, благоприятного для физического и умственного благополучия 5

Другие права «второго поколения» также могут применяться в экологических целях. Это, в частности, относится к праву на образование, которое в рассматриваемой сфере трансформируется в право на экологическое образование. Как указьвает А. Фабра, право на участие в культурной жизни, будучи достаточно защищенным, может потребовать от государства сохранять физическую окружающую среду, от которой зависит определенная культура ${ }^{6}$.

Приведенные положения доктрины международной защиты прав человека М.М. Бринчук обобщил следующим образом: «...гражданские (личные) права определяго защищенность человека, его здоровья и имущества от какого-либо незаконного вмешательства (к примеру, от вредного воздействия окружающей среды). Политические права граждан выражают возможности индивида на участие в осуществлении государственной власти (посредством проведения референдума по вопросам охраны окружающей среды, участия в процессе подго-

${ }^{5}$ О состоянии экологической безопасности в различных государствах мира с точки зрения коэффициента выживаемости, разработанного ЮНЕСКО/ВОЗ, см.: Копылов М.Н. Юридическая ответственность за экологические преступления. М.: Нзд-во РУДН, 2004. С. 13-14.

${ }^{6} \mathrm{CM}$ :: Fabra A. Indigenous Peoples, Environment Degradation and Human Rights: a Case Study. - In: Human Rights Approaches to Environmental Protection (eds. A. Boyle, M. Anderson). Oxford: Clarendon Press, 1998. P. 254-355. 
товки и принятия экологически значимых решений и др.), установления контроля за властью (путем судебного обжалования решений и действий государственных органов и должностных лиц, а также их бездействия, нарушаюших экологические права граждан). Культурные права позволяют обеспечивать рост уровня экологической культуры человека. Социальные и экономические права призваны обеспечить человеку достойный жизненный уровень с учетом экологических факторов, право на труд в экологически безопасных условиях, защиту здоровья от вредного воздействия загрязненной окружающей среды, право на экологическое образование» ${ }^{7}$.

Пересмотр содержания существующих прав. В то время как существуюшие стандарты в области прав человека предоставляют некоторые механизмы, которые могут быть использованы для защиты окружающей среды, высказывается мнение, что они недостаточны без соответствующих конвенщионшых правил толкования и применения этих прав. Следовательно, использование существующих норм не удовлетворит экологические потребности. Вместо этого действующие стандарты в области прав человека должны быть подвергнуты пересмотру в контексте экологических интересов, которых не было на момент возникновения этих прав человека.

Стандарты в области прав человека, прямо не относящиеся к проблемам окружающей среды, могут заключать в себе соответствующие предпосылки дтя их расширительного юридического толкования. Право на жизнь, например, по-видимому, следует считать нарушенным, когда государству не удается запретить или ограничить внесение высокотоксичных веществ в источники питьевой воды. Если соответствующие органы признают такие связи, тогда экологический критерий может быть включен в обеспечение права на жизнь.

Аналогичный подход вполне применим и к свободе слова, которая легко может быть направлена на выражение протеста против ущерба окружающей среде или иных экологических требований.

Новые права на окружающую среду. Хотя существующие права человека, будучи соблюдены в полной мере, могут существенно способствовать защите окружающей среды как на глобалыном, так и на местном уровнях, имеются серьезные основания полагать, что с их помощью вряд ли удастся достичь желаемых результатов. Действующие стандарты в области прав человека лишь косвенно затрагивают про-

\footnotetext{
${ }^{7}$ Бринчук М.М. Указ. соч. С. 11.
} 
блемы окружающей среды, им не хватаст точности, предлагаемые механизмы решения экологических проблем недостаточно «Гибки». Можно утверждать, что необходима норма, прямо относящаяся к окружающей среде. Мнения на этот счет расходятся, и в основном по вопросу: должны ли права на окружающую среду, если таковые нужны, быть процессуальными или материальными.

Как отмечает М. Андерсон, материальное право обеспечивает лучшую защиту окружающей среды и помогает определить необходимость и организовать поддержку природозащитной деятельности. Сторонники материалыных прав не доверягот исключительно процессуальным правам по одной простой причине: даже если процессуальные права или права на участие реализуются в полном объеме и ими справедливо пользуется все гражданское общество, очень возможно, что демократическая власть сделает выбор в пользу немедленных результатов вместо долгосрочной защиты окружагщей среды. Демократия вполне может разрушить окружаюшую среду и может быть предрасположена к чрезмерному потребительству. Действительно, индустриальные демократии Севера, со своими либеральными, основанными на праве системами, в высшей степени ответственны за значительную часть ущерба, причиненного окружающей среде, включая потребление ресурсов и выброс газов, вызывающих парниковый эффект. Одни процессуалыные права не гарантируют зашиту окружающей среды ${ }^{8}$.

С прямо противоположных позиций подходит к оценке соотношения материальньх и процессуальных прав С. Дуглас-Скотт, предлагающий вообще отказаться от закрепления первых, полагая, что целям охраны экологических интересов человека вполне могут служить иные экологические права. В числе таких прав автор называет: «право на информацию, права на участие (консультирование) и право на доступ к правосудию» ${ }^{9}$.

Возрастание числа международньх соглашений по вопросам сохранения окружающей среды и норм «мягкого» права, возникновение новых соответствуюших норм обычного права, включая решение Международного Суда о создании камеры по экологическим вопросам, де-

${ }^{8}$ Cм.: Anderson M.: Human Rights Approaches to Environmental Protection an Overview. - In: Human Rights Approaches to Environmental Protection (eds. A. Boyle, M. Anderson). Oxford: Clarendon Press, 1998. P. 8-9.

${ }^{9}$ Douglas-Scott S. Environment Rights in the EU-Participatory Democracy or Democratic Deficit? - In: Human Rights Approaches to Environment protection (eds. A. Boyle, M. Anderson)-Oxford: Clarendon press, 1998. P. 177-197. 
монстрируют признание за окружающей средой как юридического, так и политического значения, но раскрывают экологические права человека не более, чем п. 4 ст. 2 Устава ООН раскрывает предполагаемое (право на мир»).

Вряд ли более продуктивными являются и попьтки обосновать экологические права ссылками на окружающую среду в судеб̆ных решениях по делам о нарушении прав человека ${ }^{10}$.

Приведенные выше соображения, на наш взгляд, недвусмысленно указывают на необходимость выделения экологических прав в самостоятелыную категорию прав человека. Такие права расцениваготся как инструмент не только удовлетворения индивидуальных экологических интересов их обладателя, но и, что весьма важно, служат инструментом сохранения и восстановления благоприятного состояния окружающей среды как публичного блага.

Как справедливо отмечает М.И. Васильева, одно из основных экологических прав - право на благоприятную окружающую среду трудно отнести к какой-либо конкретной категории субъективных прав личности, подтверждая это выделением признаков, которые определяют статусную характеристику этого права ${ }^{11}$. Среди данных признаков она выделяет: наличие свойств личного права, так как его реализация неотделима от каждого конкретного индивида, и естественный характер данного права; присушие ему черты социально-экономических прав, политических прав (участие в принятии экологически значимых решений приближает его к политическим правам). По ее мнению, «...права признаются экологическими лишь при том условии, что сохранение качества окружающей среды и ее объектов - цель единственная и конечный интерес» ${ }^{12}$.

Российскими правоведами (прежде всего юристами-экологами) уже предпринимались попьтки классификации экологических прав человека. Так, например, А.А. Третьякова предлагает поделить все экологические права на три группы: фундаментальное экологическое право; иные экологические права (права-гарантии); смежные права ${ }^{13}$.

${ }^{10}$ Высторобец Е.А. Животный мир и право на благоприятную окружающую среду. М.: Одна восьмая, 2005. С. 18-22.

${ }^{11}$ См.: Васильева М.Н. Экологические права граждан. Тверь, 1999. С. 22.

${ }^{12}$ Васильева М.И. Публичные интересы в экологическом праве: теория и практика правового регулирования. Дис. ... Д-ра юрид. наук. М., 2003. С. 119.

${ }^{13} \mathrm{Cм.:} \mathrm{Третьякова} \mathrm{А.А.} \mathrm{Экологические} \mathrm{права} \mathrm{граждан} \mathrm{в} \mathrm{государствах} \mathrm{-} \mathrm{членах} \mathrm{Евро-}$ пейского Союза. Дис. ... к.ю.н. / МПУ. М., 2001. С. 126-127. 
Приэтом к фундаментальным экологическим правам она относит право на благоприятную окружающую среду. К иным экологическим правам (правам-гарантиям) - право на экологическую информацию, право на участие в принятии экологически значимых решений (экологические права - гарантии реализации экологических прав человека); право на возмещение экологического вреда, право требовать прекращения экологически вредной деятельности (экологические права - гарантии защиты экологических прав человека). Наконец, в категорию смежных прав она включает две группы прав: смежные экологические права (право граждан на благоприятную среду жизнедеятельности, право граждан на благоприятную среду обитания, факторы которой не оказывают вредного воздействия на человека, право на экологическую безопасность, включающее право на радиационную безопасность, право общего природопользования) и конституционные и иные права человека, смежные с экологическими (право на жизнь, право на охрану здоровья, право на труд в условиях, отвечающих требованиям безопасности и гигиены, право на участие в культурной жизни и пользование учреждениями культуры, на доступ к культурным ценностям и др.).

Соглашаясь полностью с приведенной классификацией А.А. Третьяковой,Э.Ф. Нурмухаметова предлагает дополнить категорию фундаменталыных экологических прав правом на общее природопользование. Более того, по ее мнению, правильнее выделять не смежные экологические права, а иные права человека, смежные с экологическими, поскольку право на благоприятную среду жизнедеятельности, право на благоприятную среду обитания, факторы которой не оказывают вредного воздействия на человека, и право на экологическую безопасность можно рассматривать в качестве составных элементов права на благоприятную окружающую среду ${ }^{14}$.

Достаточно подробно вопрос о классификации экологических прав разработан и в трудах М.М. Бринчука, который базируется исключительно на нормах российского экологического законодательства ${ }^{15}$.

Приведенные классификации отражают положение дел с экологическими правами человека во внутреннем законодательстве государств. Что же касается международного экологического права, принципы

${ }^{14}$ См.: Нурмухаметова Э.Ф. Международный экологический правопорядок и экологические права человека. М.: Едиториал УРСС, 2004. С. 111.

${ }^{15}$ См.: Бринчук М.М. Указ. соч. С. 9-11; Бринчук М.М. Экологическое право. М.: Юристь, 2004. С. 116-1 24, 142-174. 
которого, по нашему глубокому убеждению, должны быть едины для всех государств мира, то сегодня здесь можно считать неофициально кодифицированным на универсальном уровне только институт обеспечения соблюдения конституционных экологических прав человека, которьй нашел свое закрепление в проекте Международного Пакта по окружающей среде и развитию 1995 г., подготовленного в рамках Международного союза охраны природы и природных ресурсов (МСОП).

Основная трудность для понимания этого принципа заключается в том, что конституции болышинства государств не содержат норм (или нормы), закрепляющих экологические права человека. Соответственно, их приходится выводить из других конституционных норм. Но даже если такие нормы удается обнаружить, они значительно различаются по своему конкретному содержанию от государства к государству. Поэтому, как справедливо отмечалось в отечественной юридической литературе, сегодня принцип обеспечения конституционных экологических прав человека «нельзя толковать иным образом в отношении конкретного государства, кроме как: «что предусмотрено вашей Конституцией и конституционными законами в отношении экологических прав..., , то и соблюдайте ${ }^{16}$.

Данное обстоятельство заставляет по-новому взглянуть на те экологические права, которые закреплены в основных законах государств конституциях - и, следовательно, являгтся конституционными. Сегодня в подавляющем болышинсте случаев таковыми являготся право на благоприятную окружающую среду и право на доступ к экологической информации, за которыми практически единодушно признается характер субъективного права.

Это означает прежде всего:

- свободу поведения обладателя такого права в границах, установленных нормами права;

- возможность требовать соответствуюшего поведения (совершения известных действий или, напротив, воздержания от действий) от других (обязанных) лиц;

- возможность прибегнуть в необходимых случаях к содействию государственного аппарата, обратиться в суд за защитой нарушенного права $^{17}$.

${ }^{16}$ Копылов М.Н. Право на развитие и экологическая безопасность развивающихся стран (международно-правовыевопросы). М.: ЭКОН, 2000. С. 55; Копылов М.Н., Кузьменко Э.Ю. Международное право: кодификация и прогрессивное развитие. М.: Издво РУДН, 2005. С. 42. 
Ограниченность, а тем более отсутствие любой из этих возможностей делает ущербным то или иное субъективное право, порождает лишь видимость в обеспечении человека определенными благами.

В этой связи юридические последствия такого конституционного закрепления, по нашему мнению, сводятся к следующему: на уровне законов и подзаконньх актов возникает производная обязанность обеспечить гарантии таких экологических прав, а сам индивид получаст конституционное основание всеми законными средствами добиваться их удовлетворения.

Сказанное позволяет предложить еще одно основание для классификации экологических прав человека - по критерию их закрепления в конституциях или конституционных актах.

Отсутствие в универсальном международном праве специальных норм, кодифицирующих экологические права человека, существенно осложняет процесс их защиты. Поэтому обращает на себя внимание Конвенция ЕЭК ООН о доступе к информации, участию общественности в принятии решений и доступе к правосудию по вопросам, касающимся окружающей среды, которая была принята для региона ЕЭК ООН, охватывающего 55 государств, в 1998 г. и должна оцениваться как существенный шаг вперед по пути к такой кодификации. Данный документ не только перечислил экологические права человека относительно которых мировым сообществом уже достигнут определенный консенсус, но и раскрыл применительно к региону ЕЭК их юридическое содержание.

Одной из последних попыток сформулировать наиболее полное и содержательное определение экологических прав человека и систематизировать их явился проект Принципов «Права человека и окружающая среда», разработанный подкомиссией ООН по правам человека и окружающей среде в 1994 г.

Принятие Принципов «Права человека и окружающая среда» в виде декларации, по мнению разработчиков документа, должно придать экологическим правам автономный и определенный характер (потребность в этом уже давно назрела). В проекте предпринята попытка через общепризнанные фундаментальные права человека (например, право на жизнь, здоровье) раскрыть и выделить новый вид прав экологические права. При этом особо подчеркивается взаимосвязь

${ }^{17}$ Подробнее об этом см., например: Бринчук М.М.Экологическое право. С. 117 ; Шемшученко Ю.С. Правовыепроблемы экологии. Киев: Наукова думка, 1989. С. 23-24. 
и взаимозависимость всех существующих прав, нарушение любого из которых влечет за собой нарушение ряда других, а также взаимосвязь между сохранением окружающей среды и зашитой экологических прав.

Несомненным достоинством рассматриваемого документа является то, что он не только закрепляет экологические права, но и признает их фундаментальный характер, наряду с гражданскими, политическими, культурными, экономическими и социальными правами человека.

Из четырех известных современному международному праву видов экологических прав человека: на благоприятную окружающую среду, на доступ к экологической информации, на участие общественности в принятии решений по вопросам, касаюшимся окружающей среды, на доступ к правосудию по вопросам, касающимся окружающей среды, - особое место занимает фундаментальное право на благоприятную окружающую среду. Это предопределяется тем, что данное право, обеспечивая основы жизнедеятельности, выступает как прирожденное, имманентно присущее человеку качество. Оно опосредует специфические общественные отношения, которые, в части правопользования, не входят в предмет никаких других основньх прав, поскольку объект пользования - состояние окружающей среды - индивидуален и самодостаточен.

Право на благоприятную окружающую среду принадлежит к числу тех прав и свобод, совокупность которых дает возможность судить о положении личности в конкретном обществе, а также и о характеристиках государства. Наряду с другими социальными институтами оно определяет показатели качества жизни, и с этих позиций обеспечение благоприятной окружающей среды выступает как составная часть общих мероприятий по повышению качества жизни человека. Социальная ценность права жить в экологически безопасной среде вполне сопоставима с ценностью права на труд, отдых, охрану здоровья и др. Более того, поскольку сейчас от состояния окружающей среды все в большей степени зависит здоровье человека, успешная реализация этого права создает необходимые условия для осуществления всех других прав, свобод и интересов человека. Соответственно, загрязнение окружающей среды может рассматриваться как опосредованное нарушение всех других прав человека.

К особенностям права на благоприятную окружающую среду может быть отнесена также его сильная зависимость от внешних факторов. Внешними по отношению к условиям реализации выступа- 
ют факторы, не подверженные государственно-правовому регулированию. С одной стороны, это различные явления природного характеpa, a с другой - состояние окружающей среды и отношение к экологическим правам человека в сопредельных и даже территориально удаленных странах. В каком-то смысле право на благоприятную окружающую среду носит наднациональный характер, успешность его осуществления в пределах юрисдикции одного государства в определенной степени зависит от состояния международно-правового регулирования сферы охраны окружагщей среды. 